\title{
Prevalence of Iron Deficiency Anemia Among Female Elementary School Children in Northern Jeddah-Saudi Arabia
}

\author{
MAMDOOH A. GARI, PhD \\ Department of Medical Technology, Faculty of Applied Medical Sciences \\ and King Fahd Medical Research Center \\ King Abdulaziz University \\ Jeddah, Kingdom of Saudi Arabia \\ mgari@kau.edu.sa
}

\begin{abstract}
The aim of this study was to assess the prevalence of iron deficiency and iron deficiency anemia in relation to variables such as: age, weight, height, mother's education, number of family members, and nutritional habits among female elementary school children (age 6-12 years) in the western province of Saudi Arabia. A total of 123 female children were selected for this study. Complete blood count, serum iron, ferritin and total iron binding capacity were measured to assess iron deficiency and iron deficiency anemia. Overall, the prevalence of iron deficiency and iron deficiency anemia in this study was $23.0 \%$. Data showed that the majority of anemia cases in this study were normocytic type. Anemia was more prevalent among students of age 10-12 years as compared to younger age group. In addition, there was no relationship between iron deficiency anemia and number of family members or mother's education. Anemic students were not aware of their nutritional habits. It was concluded that iron deficiency anemia is a problem among young girls, especially among those of age 12 years in western region of Saudi Arabia. It is recommended that the iron-folate supplementation program for pregnant women be expanded to non-pregnant women, including young girls.
\end{abstract}

Keywords: Anemia, Iron deficiency anemia, Nutritional risk factor.

\section{Introduction}

Iron is essential for normal human growth. Iron is required for many essential body functions, including oxygen transport, adenosine triphosphate (ATP) production, DNA synthesis, mitochondrial function,

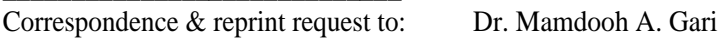

P.O. Box 80216, Jeddah 21589, Saudi Arabia

Accepted for publication: 16 June 2008. Received: 16 February 2008.

and protection of cells from oxidative damage ${ }^{[1,2]}$. Iron deficiency 
anemia is the most prevalent hematologic disorder in childhood, especially in female children ${ }^{[3]}$. It is estimated that around 2.15 billion individuals suffer from iron deficiency anemia ${ }^{[4]}$. In a recent review of the prevalence of iron deficiency anemia in the United States, 9\% of toddlers and up to $11 \%$ of adolescent girls were iron-deficient ${ }^{[2]}$. The absorption of dietary iron is assumed to be 5-10\%, but it increases 3-5 times when iron storage is depleted ${ }^{[5]}$. Inadequate dietary iron, iron absorption and intense exercise, along with blood loss and parasitic infections are some etiologies of iron deficiency anemia (IDA). Some consequences of IDA are growth retardation, exercise intolerance, behavioral changes, and abnormal thermogenesis. Although the prevalence of IDA has declined in industrialized countries, there have been few changes globally ${ }^{[6]}$. According to a UNICEF report, two billion people suffer from anemia worldwide and most of them have IDA, especially in underdeveloped/developing countries, where $40-50 \%$ of children under age 5 are iron deficient ${ }^{[7]}$. It has been reported that $46.5 \%$ of Indonesian and 30-60\% of Guatemalans under the age of 5 have suffered from IDA $^{[8,9]}$. In Iran, 30-50\% of women and children, especially those in low-income families, are suffering from iron deficiency ${ }^{[10]}$. Anemia has been shown to affect mental development and learning capacity. In infancy it may cause a permanent loss of IQ later in life, shortened attention span, irritability, fatigue, difficulty with concentration, lethargy, weakness and increased susceptibility to infection. Consequently, anemic children tend to do poorly on vocabulary, reading, and other tests ${ }^{[1]}$. In Saudi Arabia most of the studies on anemia were based on nutritional status and concentrated on preschool children who were under six years old ${ }^{[12-16]}$, so data on the nutritional status of children and adolescents in the Kingdom are insufficient ${ }^{[17,18]}$.

According to a World Health Organization (WHO) report, IDA is most frequent in children and women around the world, especially in non-industrialized countries. It is the only nutrient deficiency which is also significantly prevalent in virtually all industrialized nations. In addition, there are no current global figures for iron deficiency, but using anemia as an indirect indicator it can be estimated that most female preschool children and pregnant women in non-industrialized countries, and at least $30-40 \%$ in industrialized countries, are iron deficient ${ }^{[4,19]}$.

Therefore, the aim of this study was to assess the prevalence of iron deficiency and IDA among female elementary school students and their relation to variables such as: age, weight, height, mother's education, number of family members, and nutritional habits in Jeddah, western province of KSA. 


\section{Material and Methods}

\section{Sample selection}

During the course of this study, a total of 123 female students between the ages of 6 to 12 years old were randomly selected from a governmental school in northern Jeddah. Venous blood samples $(5 \mathrm{ml})$ were drawn from each student into ethylenediamine tetra-acetic acid (EDTA) and an additional $5 \mathrm{ml}$ blood was drawn into tubes without an added anticoagulant. EDTA blood samples were used to analyze complete blood count (CBC), whereas plain tubes were used to measure serum iron and ferritin. In addition, the weight and height of each student was recorded.

\section{Data collection}

Data for nutritional status was collected with paternal consent agreement; each student's parent was interviewed to complete a structured questionnaire over the phone, which included information on sociodemographic data, type of food taken, behavioral habits, health status in the family, and nutritional status. The type of food taken was classified into always, rarely and/or never. Mother's breast feeding was classified into natural, artificial or both. Presence of domestic helper in the home was taken to measure the social class status. The working status of the mother was also asked. Students' parents were asked if their children suffered from anemia and if so, it's type as well as other chronic diseases (such as bronchial asthma, skin allergy, etc). Data were collected by medical technology intern students trained in interviewing skills and directly supervised by the academic staff. Those reported to having hereditary anemia (such as sickle cell anemia or thalassemia) as diagnosed by a physician were excluded from the study.

\section{Methods}

CBC was measured by using Beckman coulter LH750 machine in the hematology laboratory, King Abdulaziz University Hospital, Jeddah to determine $\mathrm{CBC}$ (including hemoglobin hematocrit $\mathrm{MCV}, \mathrm{MCH}$, MCHC, RBC, RDW, WBC, and platelets). Throughout the study, Beckman coulter LH750 machine was checked and calibrated by using standard quality assurance at the beginning of the experiment.

Serum iron, ferritin and total iron capacity were measured using modular machine (Hitachi) in the Clinical Chemistry Laboratory at King Abdulaziz University Hospital, Jeddah. Throughout the study, Hitachi analyzer was checked and calibrated by using standard quality assurance at the beginning of the experiment. 
Iron deficiency was defined as ferritin $<10 \mathrm{ng} / \mathrm{ml}$ and IDA as ferritin $<10 \mathrm{ng} / \mathrm{ml}$ with hemoglobin $<10.5 \mathrm{~g} / \mathrm{dl}^{[20]}$

Participants' weight was measured without shoes and with light clothes using standard measuring scale to the nearest $0.1 \mathrm{~kg}$ and the height was taken without shoes using standard measuring tape to nearest $0.1 \mathrm{~cm}$. Equipment were recalibrated between each measurement. Body mass index (BMI) was calculated as follows: body weight $(\mathrm{Kg}) /$ height $^{2}$ (M).

\section{Data Entry and Analysis}

Data were entered and analyzed using Statistical Package for Social Sciences program (SPSS) for Windows, Version 12. Student's " $t$ " test was used to compare the proportions and $95 \%$ confidence intervals (95\% CI) between anemic and normal students in many parameters such as (height, weight, body mass index, RBCs, hemoglobin, Hct, MCV, $\mathrm{MCH}, \mathrm{MCHC})$. Differences between proportions were considered statistically significant if $95 \% \mathrm{CI}$ did not overlap. In addition, Chi-square test was used to determine the significant difference between IDA and normal group in nutritional habits of the population studied.

\section{Results}

A total of 123 Saudi female students were enrolled in this study. All students' ages ranged between 6 to 12 years. All student EDTA samples were subjected to $\mathrm{CBC}$ analysis to determine the frequency of anemia. Looking at overall $\mathrm{CBC}$ results, students were divided into two groups normal and anemic (iron deficiency and IDA) according to their age (6-9 and 10-12 years old). Table 1 summarized the $\mathrm{CBC}$ results in

Table 1. Mean and standard deviation for $\mathrm{CBC}$ results (Hb, MCV, $\mathrm{MCH}, \mathrm{MCHC}$, and RDW) and BMI, serum iron and serum ferritin in female students 6-12 years old in Jeddah.

\begin{tabular}{|c|c|c|c|c|c|c|c|c|c|c|c|c|}
\hline 范 & & 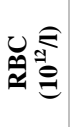 & ह & $\stackrel{0}{e}$ & $\stackrel{\Xi}{\Sigma}$ & 坖 & 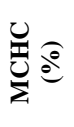 & $\widehat{2}$ & $\sum_{\infty}^{E}$ & 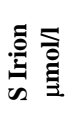 & 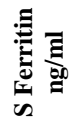 & $\begin{array}{l}\stackrel{0}{\Xi} \\
\stackrel{\Xi}{T} \\
0\end{array}$ \\
\hline \multirow{2}{*}{$6-9$} & Mean & 4.8 & 12.1 & 37.1 & 80.4 & 26.3 & 33.5 & 14.0 & 16.1 & 22.1 & 146.5 & \multirow{4}{*}{ 寸 } \\
\hline & SD & 0.3 & 1.3 & 4.9 & 6.1 & 2.1 & 0.7 & 1.2 & 2.6 & 14.4 & 121.1 & \\
\hline \multirow{2}{*}{$10-12$} & Mean & 4.7 & 11.8 & 37.8 & 79.7 & 26.7 & 33.6 & 33.5 & 18.5 & 21.0 & 157.1 & \\
\hline & SD & 0.4 & 2.0 & 3.0 & 6.0 & 2.2 & 0.7 & 0.7 & 4.7 & 13.2 & 145.5 & \\
\hline
\end{tabular}

$\mathrm{Hb}=$ Hemoglobin; $\mathrm{Hct}=$ Hematocrit $\mathrm{MCV}=$ mean corpuscular volume; $\mathrm{MCHC}=$ mean corpuscular hemoglobin

concentration; $R D W=$ Red Cell Distribution Width; BMI= Body Mass Index

each age group. The mean hemoglobin level for the first group (age 6-9 years) was $12.4 \mathrm{~g} / \mathrm{dl}( \pm 1.3)$, while the mean hemoglobin level for the 
second group was $11.8 \mathrm{~g} / \mathrm{dl}( \pm 2.0)$. Also, the median MCV was $80.4 \mathrm{fl}$ for the first group and $79.7 \mathrm{fl}$ for the second group. The ferritin levels (mean $=157.1 \mathrm{ng} / \mathrm{ml})$ were higher in female children between the ages of 10-12 (Table 1).

Overall, the prevalence of iron deficiency, and IDA in this small study was $25.2 \%$ and $10.6 \%$, respectively (Fig. 1). When the World Health Organization (WHO) cut off value for anemia was considered to be $\mathrm{Hb}<11.0 \mathrm{~g} / \mathrm{dl}$, the prevalence of anemia increased to about $30 \%$. Iron deficiency and IDA were most frequent among 10-12 year old children and the frequency decreased as age decreased (Table 2); there was significant difference between the two age groups $(p=0.024)$.

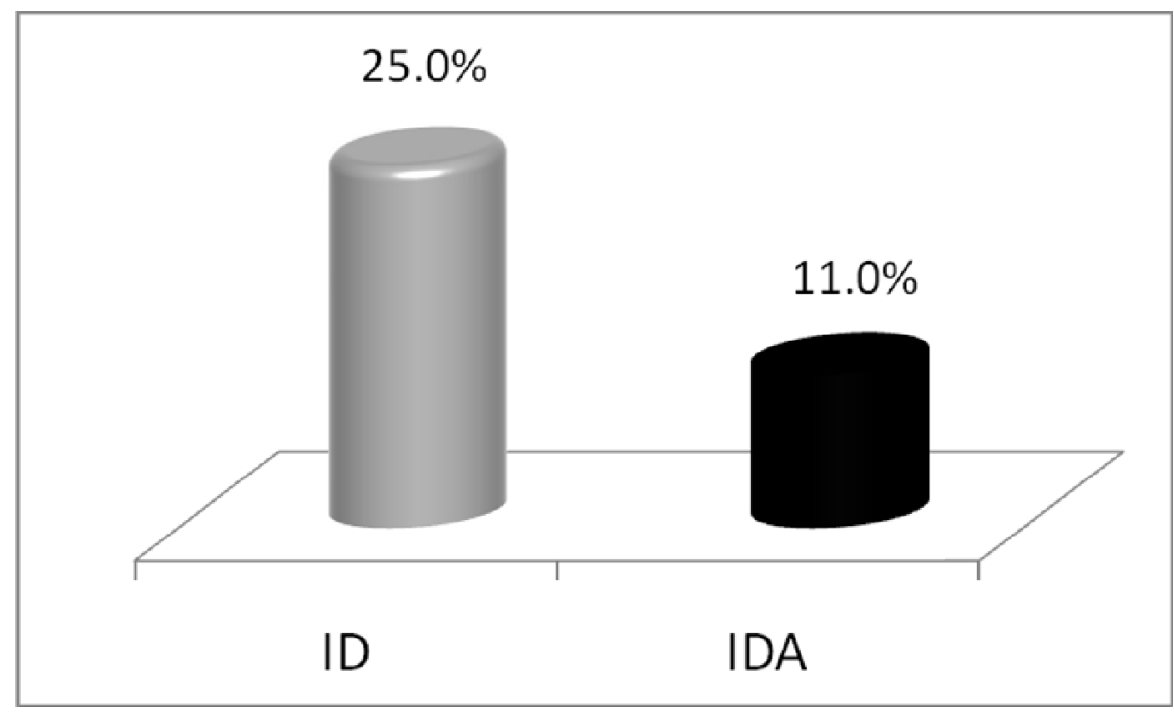

Fig. 1. The frequency of iron deficiency and iron deficiency anemia in female children 6-12 years old. ID= iron deficiency, IDA=iron deficiency anemia $(p$ Value $>0.05)$

Table 2. Distribution of iron deficiency and iron deficiency anemia (\%) among anemic female children 6-12 years old.

\begin{tabular}{c|c|c|c|c|c}
\hline \multirow{2}{*}{ Age Group } & \multirow{2}{*}{ Total Number } & \multicolumn{2}{c|}{ Iron Deficiency } & \multicolumn{2}{c}{ Iron Deficiency Anemia } \\
\cline { 3 - 6 } & & Number & Percent & Number & Percent \\
\hline $6-9$ & 64 & 13 & $10.6 \%$ & 5 & $4.1 \%$ \\
\hline $10-12$ & 59 & 18 & $14.6 \%$ & 8 & $6.5 \%$ \\
\hline \multicolumn{2}{|c|}{$p$-Value } & & & 0.024 & \\
\hline
\end{tabular}

Total number = total number of students involved in the study. The percentage shown in the table represents the frequency of iron deficiency and IDA in each age group among female students. The difference between the two groups was estimated according to their hemoglobin and ferritin levels in all anemic students investigated.

General questionnaire included: mother's work status, residence with both parents, family income, domestic helper in the home, sleeping 
time, type of feeding (breast or bottle), chronic diseases and student's school grades because these factors may play a significant factor. The majority of anemic students $(15.4 \%)$ were born to housewife mothers, while $9.8 \%$ were born to well-educated mothers. $18.7 \%$ of the students lived with both their parents. $13.8 \%$ had a domestic helper, while $13.0 \%$ were born with a chronic disease (such as asthma and diabetes mellitus). About $6.5 \%$ of anemic students were from a low income family (S.R. 1000-3000), while $18.7 \%$ were from a family of median income ( $>$ S.R. $6000)$. In addition, $8.9 \%$ of the students were naturally breast-fed while the rest of the students (16.3\%) were fed on artificial milk (Table 3 ). Overall, all these results had no statistical significant differences $(p>0.05)$.

Table 3. Distribution of socio-demographic factors and other related factors among normal and anemic students

\begin{tabular}{|c|c|c|c|c|c|c|}
\hline & & \multicolumn{2}{|c|}{ Normal } & \multicolumn{2}{|c|}{ IDA } & \multirow{2}{*}{$p$ Value } \\
\hline & & $n$ & $\%$ & $n$ & $\%$ & \\
\hline \multirow{2}{*}{$\begin{array}{l}\text { Mother's } \\
\text { working status }\end{array}$} & Yes & 48 & $39.0 \%$ & 19 & $15.4 \%$ & \multirow{2}{*}{0.195} \\
\hline & No & 44 & $35.8 \%$ & 12 & $9.8 \%$ & \\
\hline \multirow{2}{*}{$\begin{array}{l}\text { Living with } \\
\text { parents }\end{array}$} & Yes & 72 & $58.5 \%$ & 23 & $18.7 \%$ & \multirow{2}{*}{0.64} \\
\hline & No & 20 & $16.3 \%$ & 8 & $6.5 \%$ & \\
\hline \multirow{4}{*}{ Family income } & $\leq 1500$ (SR) & 3 & $2.4 \%$ & 0 & 0 & \multirow{4}{*}{0.724} \\
\hline & 3000 (SR) & 27 & $22.0 \%$ & 8 & $6.5 \%$ & \\
\hline & 6000 (SR) & 55 & $44.7 \%$ & 20 & $16.3 \%$ & \\
\hline & $\geq 9000$ (SR) & 7 & $5.7 \%$ & 3 & $2.4 \%$ & \\
\hline \multirow{2}{*}{ Domestic helper } & Yes & 52 & $42.3 \%$ & 17 & $13.8 \%$ & \multirow{2}{*}{0.87} \\
\hline & No & 40 & $32.5 \%$ & 14 & $11.4 \%$ & \\
\hline \multirow{2}{*}{ Sleeping time } & Early 9:00 p.m. & 48 & $39.0 \%$ & 14 & $11.4 \%$ & \multirow{2}{*}{0.50} \\
\hline & Late after 12:00 a.m. & 44 & $35.8 \%$ & 17 & $13.8 \%$ & \\
\hline \multirow{2}{*}{ Breast feeding } & Yes & 40 & $32.5 \%$ & 11 & $8.9 \%$ & \multirow{2}{*}{0.435} \\
\hline & No & 52 & $42.3 \%$ & 20 & $16.3 \%$ & \\
\hline \multirow{2}{*}{ Chronic diseases } & Yes & 49 & $39.8 \%$ & 16 & $13.0 \%$ & \multirow{2}{*}{0.874} \\
\hline & No & 43 & $35.0 \%$ & 15 & $12.2 \%$ & \\
\hline \multirow{3}{*}{ Student grade } & Best & 32 & $26.0 \%$ & 8 & $6.5 \%$ & \multirow{3}{*}{0.60} \\
\hline & Average & 39 & $31.7 \%$ & 16 & $13.0 \%$ & \\
\hline & Poor & 21 & $17.1 \%$ & 7 & $5.7 \%$ & \\
\hline
\end{tabular}

Regular daily food intake that included meat, liver, green vegetables and fish were reported by $9.1 \%$ of anemic students. There was no statistical difference in regular daily food intake by BMI ( $p>0.05)$.

IDA was detected among $10.6 \%$ of female students studied. Anemia was higher among older age groups (10-12 years) as compared to younger students (6-9 years). Anemia was more prevalent among students who did not eat meat, liver, green vegetables, fish, and who did not drink fresh juice. Anemia results increased among those who ate fast 
food and drank soft drinks; however, the results did not reach statistical significance. In addition, anemia was more prevalent with statistical significance in students who did not eat green vegetables on a daily basis $(p=0.01)$ and students who fed on artificial milk at infanthood $(p=0.01)$.

\section{Discussion}

The purpose of this study was to (1) assess the prevalence of iron deficiency anemia and (2) to correlate the anemia with the nutritional habit intake among female elementary school students.

Worldwide, the prevalence of anemia varies according to different conditions. In this study, the prevalence of anemia in Jeddah (iron deficiency and iron deficiency anemia) was $25.2 \%$, when anemia defined as if $\mathrm{Hb}<10.5 \mathrm{~g} / \mathrm{dl}$, but if we use WHO definition for anemia ( $\mathrm{Hb}$ $<11.0 \mathrm{~g} / \mathrm{dl}$ ), the prevalence of anemia increases to $35.8 \%$. This small research showed that the majority of anemia cases were normocytic anemia.

Previous studies performed in different regions of the Kingdom showed that the overall prevalence of anemia reported among Saudi school students in older age groups ranged from $16.1 \%^{[21]}, 20.5 \%^{[18]}$, to $26.4 \%{ }^{[17]}$. The results from other researches in developing countries showed that the prevalence of anemia in African and Southeast Asian countries and India is higher than in Saudi Arabia ${ }^{[22,23]}$. In addition, the prevalence of anemia $(\mathrm{Hb}<11 \mathrm{~g} / \mathrm{dl})$ in urban slum areas of India was $76 \%{ }^{[24]}$, and it is reported to be $27 \%$ in children between the ages of 6 months and 13 years in northern Thailand ${ }^{[25]}$. Also, the prevalence of anemia in South Cameroon in children younger than 3 years was reported to be $42 \%$ and in children between 3-5 years old, it was reported to be $21 \%{ }^{[26]}$. Nicklas et al. have reported the prevalence of anemia to be $40 \%$ in urban Haitian children $(\mathrm{Hb}<10.7 \mathrm{~g} / \mathrm{dl}$ in children younger than 2 and $\mathrm{Hb}<10.9 \mathrm{~g} / \mathrm{dl}$ in children of ages $3-5$ years ${ }^{[27]}$. Furthermore, the prevalence of iron deficiency in the United States has been reported to be $9 \%$ in children ages 6-16 years ${ }^{[5]}$. They have assumed serum ferritin < $10 \mathrm{ng} / \mathrm{ml}$ is abnormal and consider the student iron deficient when 2 of 3 tests of iron status are abnormal (Protoporphyrin of RBC, transferrin, and serum ferritin). Other groups from Switzerland have demonstrated the prevalence of IDA in school-age children to be $25 \%{ }^{[27]}$.

In this study, the prevalence of iron deficiency and IDA was higher among female children ages 10-12 years old, compared to a younger group (Table 2). This result confirms the suggestions from other 
studies that food consumed by children ages 6-9 years contain higher iron content than that consumed by older age groups, explaining the higher prevalence of anemia in children $10-12$ years ${ }^{[26,28,29]}$.

There was no relationship between iron deficiency or IDA and BMI, family income, mother's working status (mother's education), breast-feeding or chronic diseases. However, some studies have shown a high prevalence of IDA in families with lower education levels and a high number of family members. Prevalence of IDA in this study was higher in children who did not eat green vegetables. In addition, children who were not breast fed during childhood had a higher chance of developing IDA.

The lack of iron supply for hemoglobin formation that leads to development of anemia and inadequate intake of iron rich foods should be considered as contributing factors. Other factors contributing to nutritional anemia were not explored in this study, such as vitamin A deficiency and other nutrient deficiencies. Several studies have shown that poor vitamin A status is associated with low hemoglobin concentration $^{[29,30]}$. The high prevalence of anemia among young school girls in the northern area of Jeddah might lead to multiple health problems, such as impaired cognitive function, reduced school performance and poor reproductive health. These in turn would impact the future quality of human resources. The current iron-folate supplementation program for pregnant women should be expanded to non-pregnant women, including young girls. The school health program is a potential strategy to increase the iron status as well as improving the general health and nutritional status of school children. With regards to the possibility of IDA, particularly in the area where the prevalence of anemia is considered to be high, a screening procedure is suggested before an iron supplementation program is launched.

In conclusion, the burden of suffering from iron deficiency anemia in school students appears high especially among those between 10-12 years of age. Unhealthy feeding habits such as eating few vegetables and fruits and more fast foods appear to be prevalent among school students. Screening for iron deficiency anemia should be directed to high-risk groups and school programs should be implemented to improve awareness on healthy dietary habits. However, this project needs to be expanded in other areas of Jeddah, Makkah, Rabigh and other small areas to obtain the exact frequency of IDA in the western region of Saudi Arabia in order to correlate the nutritional habits. 


\section{Acknowledgment}

I would like to thank all technicians, Medical Technology interns, and students of primary school involved in this study for their kind contributions. Thanks also are due to Mrs. Sahar Jambi, King Fahd Medical Research Center for her help in statistical analysis.

\section{References}

[1] Atamna H, Walter PB, Ames BN. The role of heme and iron-sulfur clusters in mitochondrial biogenesis, maintenance, and decay with age. Arch Biochem Biophys 2002; 397(2): 345-353.

[2] McCann J, and Ames BN. An overview of evidence for a causal relation between iron deficiency during development and deficits in cognitive or behavioral function. Am J Clin Nutr 2007; 85(4): 931-945.

[3] Miller DR, Baehner RL, and Miller LP. Blood disease of infancy and childhood. $6^{\text {th }}$ ed. Mosby, Co; 1990. 170-190.

[4] FAO/WHO (1992): Preventing micronutrient deficiencies. ICN Fact Sheet No. 1. Supporting paper of the International Conference on Nutrition, December, Rome, Italy.

[5] Halterman JS, Kaczorowski JM, Aligne CA, Auinger P, Szilagyi PG. Iron deficiency and cognitive achievement among school-aged children and adolescents in the United States. Pediatrics 2001; 107(6): 1381-1386.

[6] Shinton NK.The changing practice of pathology.J Clin Pathol. 1992 45(10): 845-9.

[7] Cook JD, Skikne BS, Baynes RD. Iron deficiency: The global perspective. Adv Exp Med Biol 1994; 356: 219-228.

[8] Ross J, Horton S. Economic Consequences of Iron Deficiency report in United Nations Children's Fund (UNICEF) Focus on nutrition. The Micronutrient Initiative Publisher. 1998; $1-48$

[9] Soewondo S. The effect of iron deficiency and mental stimulation on Indonesian children's cognitive performance and development. Kobe J Med Sci 1995; 41(1-2): 1-17.

[10] Yip R. The challenge of controlling iron deficiency: Sweet news from Guatemala. Am J Clin Nut 1995; 61(5): 1164-1165.

[11] Kordas K, Lopez P, Rosado JL, Garca Vargas G, Alatorre Rico J, Ronquillo D, Cebri?n ME, Stoltzfus RJ. Blood lead, anemia, and short stature are independently associated with cognitive performance in Mexican school children. J Nutr 2004; 134(2): 363-371.

[12] Sebai ZA, El-Hamzi MAF, Serenius F. Health profile of preschool children in Tamnia villages, Saudi Arabia. Saudi Med J 1981; 2(Suppl 1): 68-71.

[13] Serenius F, Fourgerson D. Health and nutrition status in rural Saudi Arabia. Saudi Med J 1981; 2(Suppl 1): 10-22.

[14] Sebai ZA. Nutritional disorders in Saudi Arabia: a review. Fam Pract 1988; 5(1): 56-61.

[15] Al-Othaimeen AL, Sawaya WN, Tannous RI, Villanueva BP. A nutrition survey of infants and preschool children in Saudi Arabia. Saudi Med J 1988; 9(1): 40-48.

[16] Rasheed P, Al-Yousef N and Al-Dabal B. Nutrition profile of Saudi primary school girls in an urban region. Ann Saudi Med 1989; 9: 371-377.

[17] El-Hazmi MA, Warsy AS. The pattern for common anemia among Saudi children. J Trop Pediatr 1999; 45(4): 221-225.

[18] Abalkhail B, Shawky S. Prevalence of daily breakfast intake, iron deficiency anemia and awareness of being anemic among Saudi school students. Int J Food Sci Nutr 2002; 53(6): 519-528.

[19] Gleason G, Gross R, Viteri F, Yip R. Indicators and Strategies for Iron Deficiency Anemia Programs. Report of the WHO/UNICEF/UNU Consultation. 1998, Oslo, Norway.

[20] Karimi M, Mirzaei M, Dehghani A. Prevalence of anemia, iron deficiency and iron deficiency anemia in 6-60 month old children in Yazd's rural area. Intern Pediatr 2004; 19(3): $180-184$. 
[21] Al-Othaimeen A, Osman AK, Al Orf S. Prevalence of nutritional anemia among primary school girls in Riyadh City, Saudi Arabia. Int J Food Sci Nutr 1999; 50(4): 237-243.

[23] Gomber S, Kumar S, Rusia U, Gupta P, Agarwal KN, Sharma S. Prevalence etiology of nutritional anaemias in early childhood in an urban slum. Indian J Med Res 1998; 107: 269-273.

[24] Linpisarn S, Tienboon P, Promtet N, Putsyainunt P, Santawanpat S, Fuchs GJ. Iron deficiency and anaemia in children with a high prevalence of haemoglobinopathies: implications for screening. Int J Epidemiol 1996; 25(6): 1262-1266.

[25] Cornet M, Le Hesran JY, Fievet N, Cot M, Personne P, Gounoue R, Beyeme M, Deloron P. Prevalence of and risk factors for anemia in young children in southern Cameroon. Am J Trop Med Hyg 1998; 58(5): 606-611.

[26] Nicklas TA, Kuvibidila S, Gatewood LC, Metzinger AB, Frempong KO. Prevalence of anaemia and iron deficiency in urban Haitian children two to five years of age. J Trop Pediatr 1998; 44(3): 133-138.

[27] Asobayire FS, Adou P, Davidsson L, Cook JD, Hurrell RF. Prevalence of iron deficiency with and without concurrent anemia in population groups with high prevalences of malaria and other infections: a study in Côted' Ivoire. Am J Clin Nutr 2001; 74(6): 776782.

[28] Bloem MW, Wedel M, Egger RJ, Speek AJ, Schrijver J, Saowakontha S, Schreurs WH. Iron metabolism and vitamin A deficiency in children in northeast Thailand. Am J Clin Nutr 1989; 50(2): 332-328.

[29] Wolde-Gebriel Z, West CE, Gebru H, Tadesse AS, Fisseha T, Gabre P, Aboye C, Ayana G and Hautvast JG. Interrelationship between vitamin A, iodine and iron status in schoolchildren in Shoa Region, Central Ethiopia. Br J Nutr 1993; 70(2): 593-607. 
نسبة نقص الحديد في الدم في طالبات المرحلة الابتدائية في شمال جدة

\begin{abstract}
مدوح بن عبد الله قاري
المستخلص. تعتبر نسبة نقض الحديد في سكان الولايات المتحدة

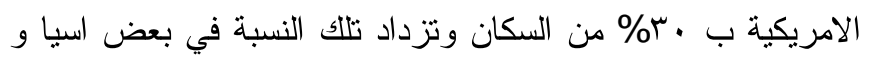

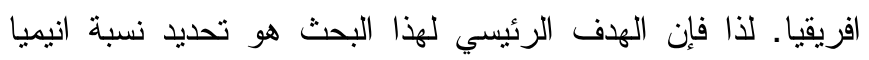

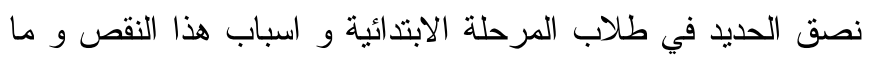

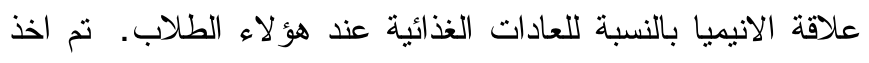

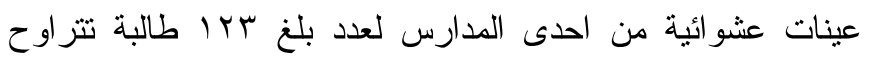

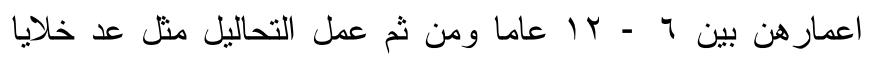

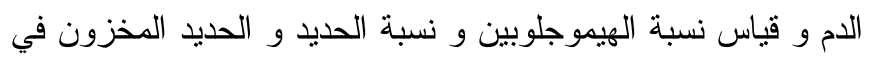

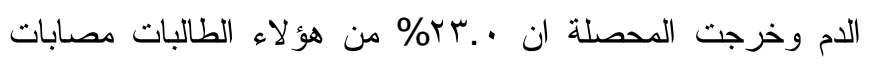

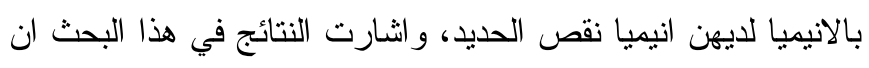

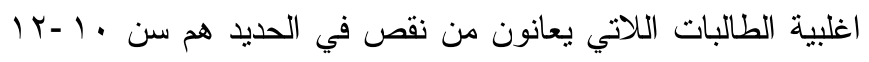

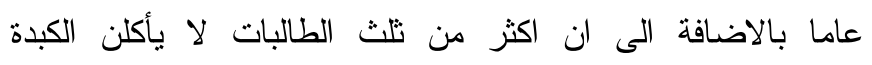

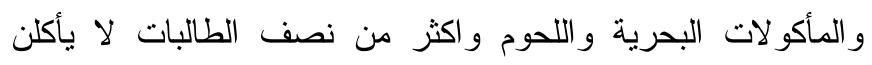

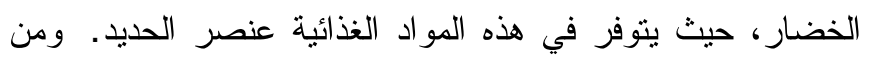
التوصيات التي توصي بها نتائج هذا البحث هي الاكثار من الحملات

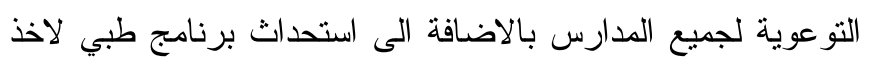

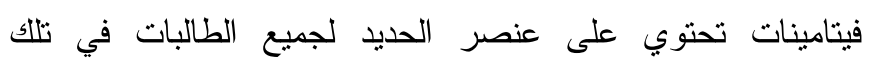
المرحلة الدراسية.
\end{abstract}

